\title{
Non-alcoholic Fatty Liver Disease (NAFLD) is associated with impairment of Health Related Quality of Life (HRQOL)
}

Pegah Golabi', Munkhzul Otgonsuren ${ }^{1}$, Rebecca Cable², Sean Felix', Aaron Koenig ${ }^{1}$, Mehmet Sayiner ${ }^{1}$ and Zobair M. Younossi ${ }^{1,2^{*}}$

\begin{abstract}
Background: NAFLD impacts patient reported outcomes (PROs). Our aim was to assess the impact of NAFLD on patients' HRQOL.

Methods: National Health and Nutrition Examination Survey (NHANES) 2001-2011 data were used to identify adult patients with NAFLD [Fatty Liver Index (FLI) $>60$ in absence of other liver disease and excessive alcohol $>20 \mathrm{~g} /$ day for men, >10 g/day for women]. Patients with other chronic diseases (ex. HIV, cancer, end-stage kidney disease) were excluded. Subjects without any of these conditions were healthy controls. HCV RNA (+) patients were HCV-controls. All patients completed NHANES HRQOL-4 questionnaire. Linear regression determined the association between NAFLD and HRQOL components adjusting for age, gender, race, and BMI.

Results: Participants with complete data were included ( $n=9661$ ); 3333 NAFLD (age 51 years and BMI $34 \mathrm{~kg} / \mathrm{m}^{2}$ ); $346 \mathrm{HCV}+$ (age 49 years; BMl $27 \mathrm{~kg} / \mathrm{m}^{2}$ ) and 5982 healthy controls (age 48 years and BMl $26 \mathrm{~kg} / \mathrm{m}^{2}$ ). The proportion of subjects rating their health as "fair" or "poor" in descending order were HCV controls (30 \%) NAFLD (20 \%) and healthy controls $(10 \%)(p<0.001)$. HRQOL-4 components scores $2-4$ were lowest for HCV, followed by NAFLD and then healthy controls ( $p$-values $p=0.011$ to $<.0001$ ). After adjustment for age, gender, race, and BMI, NAFLD patients were 18-20\% more likely to report days when their physical health wasn't good or were unable to perform daily activities as a result $(p<.0001)$.
\end{abstract}

Conclusions: NAFLD causes impairment of HRQOL. As NAFLD is becoming the most important cause of CLD, its clinical and PRO impact must be assessed.

\section{Background}

Non-alcoholic fatty liver disease (NAFLD) is an important cause of chronic liver disease worldwide [1-5]. NAFLD has been associated with cirrhosis, hepatocellular carcinoma and is currently the second indication for liver transplantation [6].

NAFLD is increasingly being diagnosed in patients with nonspecific symptoms with incidental elevation

\footnotetext{
* Correspondence: Zobair.younossi@inova.org

${ }^{1}$ Betty and Guy Beatty Center for Integrated Research, Inova Health System, Falls Church, VA, USA

${ }^{2}$ Center For Liver Disease, Department of Medicine, Inova Fairfax Hospital,

Falls Church, VA, USA
}

of aminotransferases [7, 8]. Besides fatigue, NAFLD patients may also experience other symptoms such as anxiety, depression, cognitive impairment, and loss of self-esteem [9]. These symptoms significantly impact patients' well-being and health-related quality of life (HRQOL) [10]. Although the impact of chronic hepatitis $C$ infection on HRQOL has been reported extensively, there is little published data about HRQOL assessment in patients with NAFLD. Therefore, our aim was to assess the impact of NAFLD on patients' HRQOL as compared to HRQOL impairment in patients with $\mathrm{CH}-\mathrm{C}$ and those without liver disease. 


\section{Methods}

\section{Study design and population}

Availability of data and materials: National crosssectional health survey data [National Health and $\mathrm{Nu}$ trition Examination Survey (NHANES) conducted between 2001 and 2011] were used. The Center for Disease Control and Prevention (CDC) collected the data by an interviewer-administered questionnaire conducted in participants' homes by trained interviewers. Clinical data were obtained through the use of specially designed and equipped mobile examination centers. Participants $(n=49,762)$ were excluded if they had Alcoholic Liver Disease (ALD) (alcohol consumption of $\geq 20 \mathrm{~g} /$ day for men, $\geq 10 \mathrm{~g} /$ day for women over past 12 months), other chronic diseases such as HIV, cancer, end-stage kidney disease and/or had missing data on key variables (demographic and HRQOL), (Fig. 1- Flow chart for Eligibility, NHANES, 2001-2012)

\section{Sociodemographic variables}

Age (years), gender, race/ethnicity (white, black, other), education (less than high school, high school, college or above), annual household income (less than $\$ 55,000$ per year, $\$ 55,000$ or more) were selfreported. Anthropometric measurements (height, weight) were obtained by trained staff during the medical examination.

\section{Definitions of chronic liver diseases}

The following liver diseases were identified and included in the study: (1) Chronic Hepatitis $C$ diagnosis was based on a positive Hepatitis $\mathrm{C}$ antibody (ELISA II analysis) or HCV RNA as detected by polymerase chain reaction; (2) NAFLD was determined by the Fatty Liver Index (FLI). A FLI score of 60 or more in the absence of $\mathrm{HCV}, \mathrm{HBV}$ and significant alcohol consumption was NAFLD; and (3) Participants without any chronic liver diseases and a FLI score $\leq 30$ were considered as Healthy Controls.

\section{Assessment of quality of life}

Four components of a participants' health-related quality of life (HRQOL-4) over a previous 30-day period were assessed during the scheduled visit. The four component questions were: Component 1 (C1): Rate your health status as poor, fair, good, very good, or excellent. ; (b) C2 Thinking about your physical health, which includes physical illness and injury, for how many days during the past 30 days was your physical health not good; (c) C3 Thinking about your mental health, which includes stress, depression, and problems with emotions, for how many days during the past 30 days was your mental health not good; and (d) C4 About how many days did poor physical or mental health keep him/her from doing your usual activities, such as self-care, work, or recreation.

\section{Data analyses}

For analyses, participants were divided into two groups: fair/poor coded as "1" and good/very good/excellent were coded as "0" for component 1. For components $\mathrm{C} 2-\mathrm{C} 4$, we coded participants who reported no poor

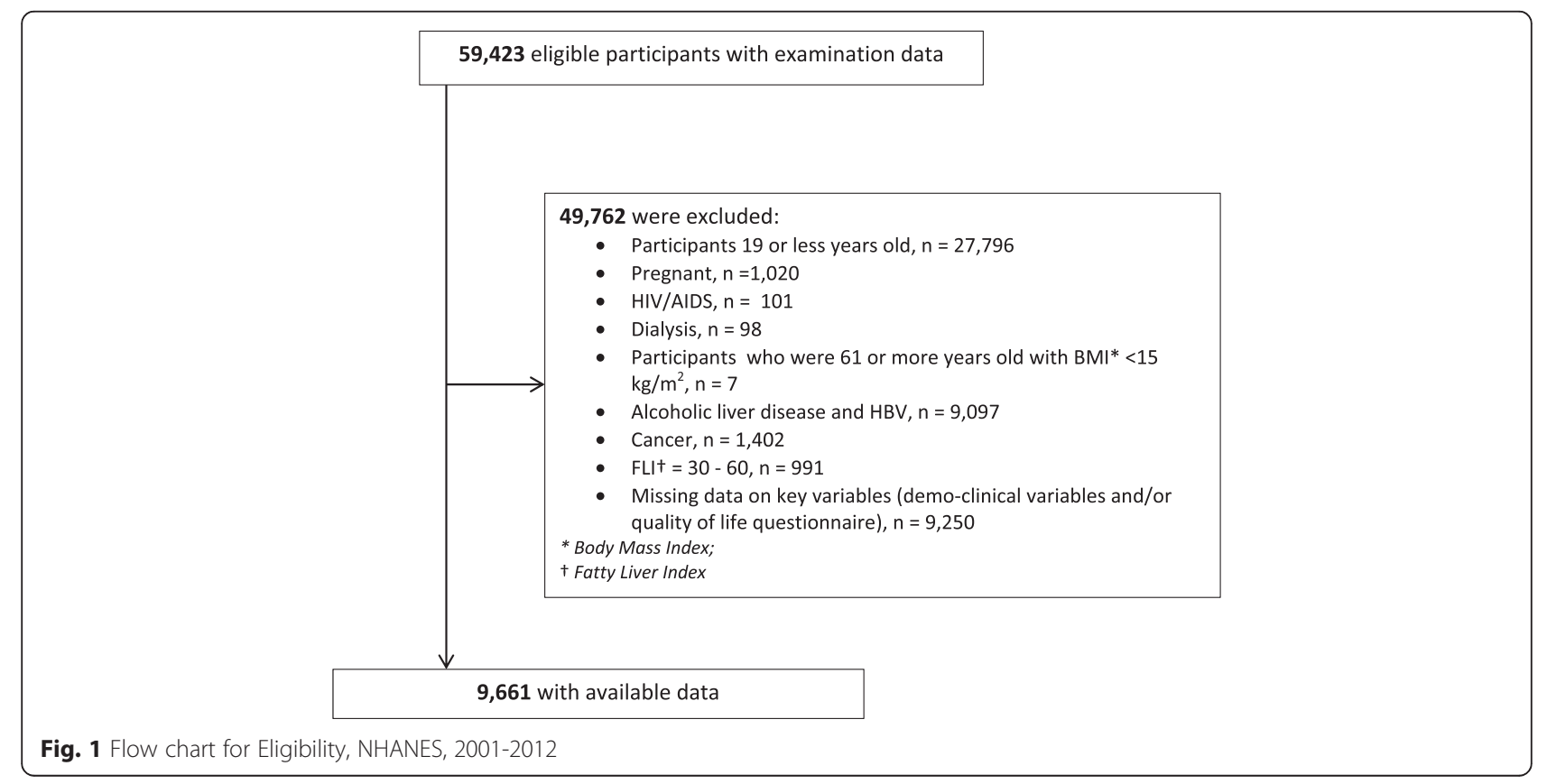


days (50 \% of participants) as " 0 " and coded the others who reported any number of days $>0$ as " 1 ".

Simple logistic regression models with linearized variance estimation and weighting were used to estimate the association between self-reported quality of life questionnaire (for each component of C1-C4, separately) and liver disease while adjusting for age, gender, race, BMI, smoking, education, diabetes, and heart disease. We did not adjust household income in the final model due to a high correlation with education (Spearman rank-order rho $=0.40, \quad P<.0001$ ). Spearman rank-order correlations were estimated to examine an association between the participants' ranking their health condition $(\mathrm{C} 1)$ and demographic variables stratified by liver disease. SAS V9.3 was used for analyses (SAS Institute, Cary, NC). To account for the complex survey design from NHANES, SAS survey command with sampling weight, stratification and clustering variables were used except for Spearman's rank-order correlation analyses.

\section{Results}

Subjects' baseline characteristics

A total of 9661 participants with complete data were enrolled in the study (Table 1). Of these, 346 patients had HCV, 3333 had NAFLD and 5982 were considered controls. Mean age of the patients was 48.8 years $(48.8 \pm$ $0.50, p<.0001$ in HCV, $51.3 \pm 0.36, p<.0001$ in NAFLD and $47.5 \pm 0.39, p<.0001$ in Control). NAFLD patients had significantly higher body mass index (BMI) as compared to the Controls $(33.66 \pm 0.14$ vs $26.22 \pm 0.10$, $p<.0001)$ and HCV patients $(33.66 \pm 0.14$ vs $27.26 \pm$ $0.41, p<.0001)$. Of the NAFLD cohort, $57.8 \%$ were male and $72.4 \%$ were White. Furthermore, metabolic syndrome components such as hyperlipidemia, hypertension, and insulin resistance were more common in the NAFLD group, as well as history of heart disease (all $p<.001$ ).

\section{Health related quality of life in NAFLD}

Component 1 of HRQOL questionnaire Component 1 of HRQOL was concerned with overall HRQOL

Table 1 Characteristics of Study by Liver Disease, NHANES, 2001-2012

\begin{tabular}{|c|c|c|c|c|c|c|}
\hline Variables & $\begin{array}{l}\mathrm{HCV} \\
(n=346)\end{array}$ & $\begin{array}{l}\text { NAFLD } \\
(n=3333)\end{array}$ & $\begin{array}{l}\text { Control } \\
(n=5982)\end{array}$ & $P$ value $^{a}$ & $P$ value $^{b}$ & $\overline{P \text { value }}$ \\
\hline Age (years): mean (SE) & $48.86(0.50)$ & $51.31(0.36)$ & $47.50(0.39)$ & 0.058 & $<.0001$ & $<.0001$ \\
\hline Body Mass Index $\left(\mathrm{kg} / \mathrm{m}^{2}\right)$ : mean (SE) & $27.26(0.41)$ & $33.66(0.14)$ & $26.22(0.10)$ & 0.037 & $<.0001$ & $<.0001$ \\
\hline Male & $228(66.87 \%)$ & 1817 (57.79 \%) & $3103(50.03 \%)$ & $<.0001$ & $<.0001$ & 0.014 \\
\hline Race, & & & & $<.0001$ & 0.034 & $<.0001$ \\
\hline White & $134(63.53 \%)$ & $1612(72.46 \%)$ & $3221(75.15 \%)$ & & & \\
\hline Black & $137(22.87 \%)$ & $684(10.88 \%)$ & $1164(9.50 \%)$ & & & \\
\hline Other & $75(13.60 \%)$ & $1037(16.66 \%)$ & $1597(15.35 \%)$ & & & \\
\hline \multicolumn{7}{|l|}{ Comorbid disease, } \\
\hline Diabetes & $56(13.03 \%)$ & 918 (20.75 \%) & $503(6.05 \%)$ & $<.0001$ & $<.0001$ & 0.010 \\
\hline Hyperlipidemia & $177(44.12 \%)$ & 2051 (57.01\%) & $2286(32.50 \%)$ & $<.0001$ & $<.0001$ & $<.0001$ \\
\hline High blood pressure & 119 (29.46 \%) & 2020 (58.99 \%) & $2351(38.35 \%)$ & 0.009 & $<.0001$ & $<.0001$ \\
\hline Insulin resistance & $81(47.34 \%)$ & 2147 (66.03 \%) & 442 (12.24 \%) & $<.0001$ & $<.0001$ & $<.0001$ \\
\hline Heart disease & 47 (9.46 \%) & $540(13.83 \%)$ & 558 (6.79 \%) & 0.119 & $<.0001$ & 0.040 \\
\hline Asthma & 44 (14.62 \%) & 394 (12.69 \%) & 433 (7.87 \%) & 0.001 & $<.0001$ & 0.468 \\
\hline NHANES cycle, & & & & 0.135 & 0.696 & 0.152 \\
\hline 2001-2002 & 71 (24.07 \%) & 541 (16.24 \%) & 1022 (16.73 \%) & & & \\
\hline 2003-2004 & 49 (16.81\%) & 534 (17.15 \%) & 856 (15.29 \%) & & & \\
\hline 2005-2006 & $41(13.80 \%)$ & 499 (16.98 \%) & 893 (16.47 \%) & & & \\
\hline 2007-2008 & 75 (18.37 \%) & 630 (17.07 \%) & 1056 (16.63 \%) & & & \\
\hline 2009-2010 & $53(11.37 \%)$ & 602 (15.22 \%) & 1117 (16.74 \%) & & & \\
\hline 2011-2012 & $57(15.58 \%)$ & 527 (17.35 \%) & 1038 (18.13 \%) & & & \\
\hline
\end{tabular}

Pvalues were reported by chi-square test for categorical variables and t-test for numerical variables;

${ }^{a}$ Comparisons between HCV and Control

${ }^{b}$ Comparisons between NAFLD and Control

${ }^{c}$ Comparisons between HCV and NAFLD 
Table 2 HRQOL in Participants with NAFLD and HCV, NHANES, 2001-2012

\begin{tabular}{|c|c|c|c|c|c|c|}
\hline Variables & $\begin{array}{l}\mathrm{HCV} \\
(n=346)\end{array}$ & $\begin{array}{l}\text { NAFLD } \\
(n=3333)\end{array}$ & $\begin{array}{l}\text { Control } \\
(n=5982)\end{array}$ & $P$ value ${ }^{a}$ & $P$ value $^{b}$ & $P$ value $^{c}$ \\
\hline \multicolumn{7}{|c|}{ HRQOL-4 components, } \\
\hline $\mathrm{C} 1$ & & & & $<.0001$ & $<.0001$ & 0.005 \\
\hline Excellent & 20 (7.19\%) & $201(6.49 \%)$ & $863(17.36 \%)$ & & & \\
\hline Very good/Good & $201(60.75 \%)$ & $2112(71.02 \%)$ & 4215 (72.22 \%) & & & \\
\hline Fair & $98(24.81 \%)$ & $831(18.83 \%)$ & $806(9.09 \%)$ & & & \\
\hline Poor & $27(7.24 \%)$ & 189 (3.66 \%) & $98(1.32 \%)$ & & & \\
\hline $\mathrm{C} 2$ (no day = 0 ) & 187 (52.47 \%) & $2000(61.34 \%)$ & $4048(68.31 \%)$ & $<.0001$ & $<.0001$ & 0.012 \\
\hline C3 (no day = 0) & $175(46.58 \%)$ & $2174(64.07 \%)$ & $3868(62.60 \%)$ & $<.0001$ & 0.257 & $<.0001$ \\
\hline C4 (no day $=0$ ) & $230(64.96 \%)$ & $2663(79.84 \%)$ & $5050(84.41 \%)$ & $<.0001$ & $<.0001$ & $<.0001$ \\
\hline
\end{tabular}

$P$ values were reported by chi-square test;

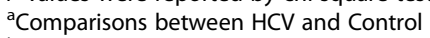

${ }^{b}$ Comparisons between NAFLD and Control

${ }^{c}$ Comparisons between HCV and NAFLD

assessment (Table 2, Fig. 2). The proportion of participants who rated their health as excellent or very good was significantly higher in the Control group as compared to both NAFLD and HCV groups (90 vs 78, $68 \%$, respectively; $p<.0001)$. The overall HRQOL score was lowest for $\mathrm{HCV}$ and then NAFLD patients.

Component 2 of HRQOL questionnaire Component 2 was mostly involved with number of days with physical health issues. In fact, the control group was more likely to report no days of having physical health problems compared to the NAFLD group ( 68.3 vs $61.3 \%, p<.001$ ). On the other hand, $\mathrm{HCV}$ patients were least likely to report no days of having physical health problems (52.4\%).
Component 3 of HRQOL questionnaire Component 3 was concerned with number of days with mental health issues. In this context, NAFLD patients reported similar mental health issues to the controls (62.6 vs $64 \%$, $\mathrm{p}>0.05)$. On the other hand, $\mathrm{HCV}$ patients were less likely to report no days of having mental health problem, compared to controls and NAFLD patients (46.5 vs 62.6 and $64 \%, p<0.01)$.

Component 4 of HRQOL questionnaire Component 4 was concerned with number of days that the physical and mental health issues would prevent patients from their activities. Again, the control group had significantly fewer number of days that physical or mental health

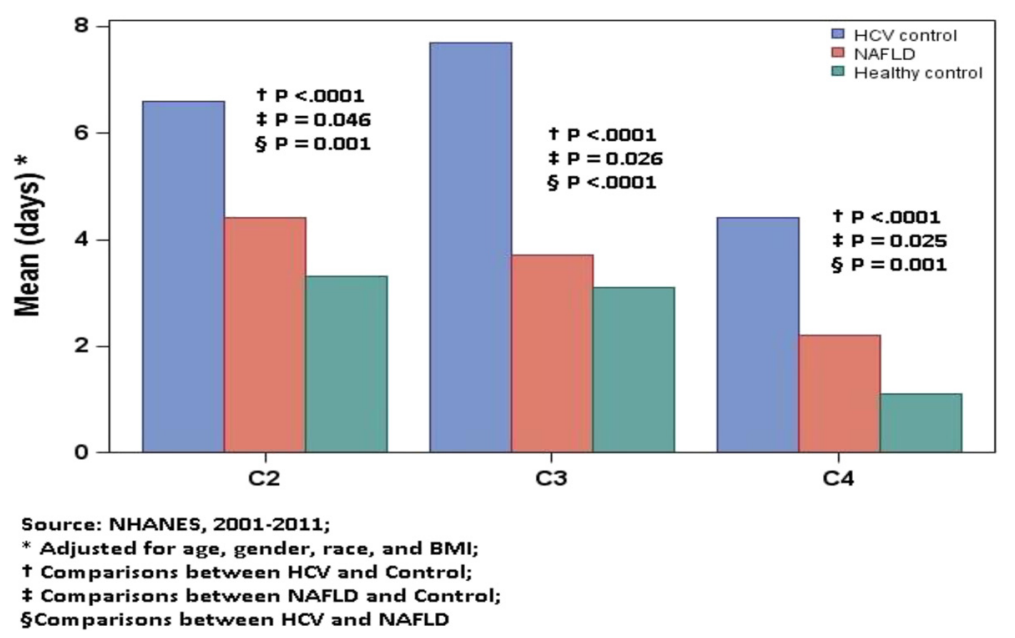

Fig. 2 Adjusted* mean HRQOL components (C2-C4) by liver disease, and pair-wise comparisons (t-test), NHANES, 2001-2011 
kept the participants away from doing their usual activities (self-care, work, or recreation) during last 30 -days compared to the NAFLD group $(84.4 \%$ in the Control group reported zero effected days vs. $79.8 \%$ in NAFLD; $p<.0001)$. HCV patients had the worst score with only $64.9 \%$ in this group reporting zero effected day $(p<.0001)$.

After adjusting for age, gender, race, and BMI, the association between PRO impairment and the diagnosis of HCV (C1-C4) and NAFLD (C1, C2 and C4) remained significant (Table 3).

(Figure 2: Adjusted* mean HRQOL components $(\mathrm{C} 2-\mathrm{C} 4)$ by liver disease, and pair-wise comparisons (t-test), NHANES, 2001-2011).

\section{Discussion}

Patient reported outcomes (PROs) such as HRQOL are surrogates for a patient's experience [11]. Assessing PROs are important to accurately estimate the burden of chronic liver disease and its treatment on patients' well-being. In this study, we used population-based data to assess HRQOL in patients with NAFLD. Our data analysis showed that NAFLD patients indeed experienced significant impairment of their HRQOL. In this context, almost one fourth (22\%) of NAFLD patients reported their health as being poor or fair which was significantly more than the healthy controls $(10 \%)$. Furthermore, this impairment resulted in a reduction of patients' ability to perform their daily activities. Interestingly, NAFLD patients had more impairment of their physical health than their mental health. These data are partially consistent with the data previously reported showing NAFLD patients have PRO burden related to bodily pain, shortness of breath and muscle cramps as well as anxiety, unhappiness, being irritable and having mood swings [12]. Furthermore, our data is consistent with HRQOL assessment using Short Form-36 questionnaire reporting impairment in physical functioning (how much physical activities are limited), role physical (how much physical health impacts work and daily activities), bodily pain (limitations because of pain), vitality (how tired/full of energy subject feels), and role emotional (the impact of emotional problems on work and daily activities) [13].

Although not exactly clear, the reported poor physical health in NAFLD patients may be related to fatigue. Fatigue has been shown in previous studies to be a significant problem for NAFLD patients [8, 14-16]. In fact, in one such study, autonomic dysfunction and fatigue were both common in NAFLD [14, 17]. This could provide some mechanistic pathway for the development of fatigue in patients with NAFLD.

It is also important to note that impairment of HRQOL in NAFLD was less pronounced than those with HCV. In fact, the mental health aspect of PROs was more profoundly affected in HCV than NAFLD. This is not a surprise given the strong association of HRQOL with depression in patients with $\mathrm{HCV}$ [18-20].

\section{Conclusion}

In conclusion, NAFLD is associated with impairment of patients' HRQOL. Since previous studies reporting association of NAFLD with PRO impairment (12-13) were reported from the tertiary care centers, their results could have been associated with referral bias. This current study using large population database from NHANES provides additional data documenting impairment of HRQOL in patients with NAFLD. This integrated approach to understanding the clinical and PRO burden of NAFLD can provide a more comprehensive approach to treatment and management of patients with NAFLD.

\section{Ethics approval}

This study was approved by the IRB, the approval number is NHANES IRB: 12.1074 .

\section{Availability of data}

In this study, NHANES data was used, which is available online at NHANES website.

Table 3 Adjusted* odds ratios (OR) with 95 \% confidence intervals (Cls) for each outcome of HRQOL, NHANES, 2001-2012 (reference for $\mathrm{C} 1$ = excellent/very good/good and for C2-C4 = no days)

\begin{tabular}{lllll}
\hline & $\mathrm{C} 1$ & $\mathrm{C} 2$ & $\mathrm{C3}$ & $\mathrm{C}$ \\
\hline Variable & $\mathrm{OR}^{\mathrm{a}}(95 \% \mathrm{Cl})$ & & Reference & Reference \\
Control & Reference & Reference & $1.98(1.52-2.58)$ & $2.83(2.05-3.90)$ \\
HCV & $2.07(1.48-2.88)$ & $1.82(1.36-2.43)$ & $0.95(0.82-1.10)$ & $1.20(1.02-1.41)$ \\
NAFLD & $1.22(1.03-1.44)$ & $1.18(1.03-2.08)$ &
\end{tabular}

\footnotetext{
${ }^{a}$ Adjusted for age, gender, race, BMI, education, income, smoking status, diabetes, and heart disease
} 


\section{Appendix}

Table 4 Spearman rho correlation for rating* their health status as poor to excellent (C1 component) with demographic variables, stratified health conditions, NHANES, 2001-2012

Variables

\begin{tabular}{lllll} 
rho, $\mathrm{P}$ & \multicolumn{5}{l}{} \\
\hline Total (overall), & $\mathrm{HCV}$ & $\mathrm{NAFLD}$ & Heart disease & $\begin{array}{l}\text { Diabetes } \\
n=9661\end{array}$ \\
$n=346$ & $n=3333$ & $n=1145$ & $n=1477$ \\
\hline $0.14,<0.01$ & $0.11,0.03$ & $0.10,<0.01$ & $-0.12,<0.01$ & $-0.06,0.06$ \\
$0.23,<0.01$ & $0.16,0.04$ & $0.12,<0.01$ & $0.16,<0.01$ & $0.13,<0.01$ \\
$-0.06,<0.01$ & $-0.11,0.08$ & $-0.16,<0.01$ & $-0.12,<0.01$ & $-0.13,<0.01$ \\
$-0.19,<0.01$ & $-0.10,0.09$ & $-0.16,<0.01$ & $-0.20,<0.01$ & $-0.14,<0.01$ \\
$0.06,<0.01$ & $0.08,0.30$ & $-0.01,0.44$ & $0.11,<0.01$ & $0.02,<0.01$ \\
$0.15,<0.01$ & $0.04,0.43$ & $0.18,<0.01$ & $0.13,<0.01$ & $0.13,<0.01$ \\
$0.30,<0.01$ & $0.45,<0.01$ & $0.34,<0.01$ & $0.41,<0.01$ & $0.39,<0.01$ \\
$0.17,<0.01$ & $0.30,<0.01$ & $0.21,<0.01$ & $0.28,<0.01$ & $0.26,<0.01$ \\
$0.21,<0.01$ & $0.39,<0.01$ & $0.24,<0.01$ & $0.28,<0.01$ & $0.27,<0.01$
\end{tabular}

Age (years)

Body Mass Index (BMI) $\left(\mathrm{kg} / \mathrm{m}^{2}\right)$

Gender ( $1=$ male and $0=$ female)

White $(1=$ yes and $0=$ no)

$0.39,<0.01$

$0.28,<0.0$

$0.27,<0.0$ him/her from doing your usual activities, such as self-care, work, or recreation not good

*Ranges from 1 to 5 with a higher score indicates worse self-health assessment $(1=$ excellent; $2=$ very good; $3=$ good; $4=$ fair; and $5=$ poor)

\section{Abbreviations}

ALD: alcoholic liver disease; BMI: body mass index; CDC: center for disease control and prevention; $\mathrm{CH}-\mathrm{C}$ : chronic Hepatitis C; CLD: chronic liver disease; FLI: fatty liver index; HRQOL: health related quality of life; NAFLD: nonalcoholic fatty liver disease; NHANES: National Health and Nutrition Examination Survey; PRO: patient reported outcome.

\section{Competing interests}

The authors declare that they have no competing interests.

\section{Authors' contributions}

PG participated in the study design, helped the interpretation of the data and to draft the manuscript. MO performed the statistical analysis and helped the interpretation of the data. MS participated in the interpretation of the data and revised the manuscript. RC, SF and AK made contributions to the study design as well as interpretation of the data. ZY conceived of the study, participated substantially in its design and coordination, and helped to draft the manuscript. All authors read and approved the final manuscript.

\section{Acknowledgments}

We would like to thank Brian Lam and Beatty Liver \& Obesity Research Program staff for their great support during the formation of this study.

\section{Funding}

This study was internally funded without any external reimbursement, fee or salary.

Received: 11 November 2015 Accepted: 27 January 2016

Published online: 09 February 2016

\section{References}

1. Hamaguchi M, Takeda N, Kojima T, Ohbora A, Kato T, Sarui H, et al. Identification of individuals with non-alcoholic fatty liver disease by the diagnostic criteria for the metabolic syndrome. World J Gastroenterol. 2012; 18:1508-16.

2. Dyson JK, Anstee QM, McPherson S. Non-alcoholic fatty liver disease: a practical approach to treatment. Frontline Gastroenterol. 2014;5:277-86.
3. Younossi ZM, Otgonsuren M, Henry L, Venkatesan C, Mishra A, Erario M, et al. Association of Non-alcoholic Fatty Liver Disease (NAFLD) with Hepatocellular Carcinoma (HCC) in the United States from 2004-2009. Hepatology. 2015. doi:10.1002/hep.28123.

4. Rinella ME. Nonalcoholic fatty liver disease: a systematic review. JAMA. 2015; 313:2263-73.

5. Chalasani N, Younossi Z, Lavine JE, Diehl AM, Brunt EM, Cusi K, et al. The diagnosis and management of non-alcoholic fatty liver disease: practice Guideline by the American Association for the Study of Liver Diseases, American College of Gastroenterology, and the American Gastroenterological Association. Hepatology. 2012;55:2005-23.

6. Wong RJ, Aguilar M, Cheung R, Perumpail RB, Harrison SA, Younossi $Z M$, et al. Nonalcoholic steatohepatitis is the second leading etiology of liver disease among adults awaiting liver transplantation in the United States. Gastroenterology. 2015;148:547-55.

7. Younossi ZM, Henry L. Economic and quality-of-life implications of Non-alcoholic fatty liver disease. Pharmacoeconomics. 2015;33(12):1245-53. doi:10.1007/s40273-015-0316-5. PMID: 26233836.

8. Newton JL. Systemic symptoms in non-alcoholic fatty liver disease. Dig Dis. 2010;28:214-9.

9. Mahmood S. Assessment of health related quality of life in chronic liver disease patients using the Japenese versions of CLDQ and SF-36. Open Gastroenterol J. 2008;2:57-63.

10. Loria A, Escheik C, Gerber NL, Younossi ZM. Quality of life in cirrhosis. Curr Gastroenterol Rep. 2013;15:301.

11. Younossi ZM, Stepanova M, Nader F, Lam B, Hunt S. The patient's journey with chronic hepatitis $C$ from interferon plus ribavirin to interferon- and ribavirin-free regimens: a study of health-related quality of life. Aliment Pharmacol Ther. 2015;42:286-95.

12. Dan AA, Kallman JB, Wheeler A, Younoszai Z, Collantes R, Bondini S, et al. Health-related quality of life in patients with non-alcoholic fatty liver disease. Aliment Pharmacol Ther. 2007:26:815-20.

13. Afendy A, Kallman JB, Stepanova M, Younoszai Z, Aquino RD, Bianchi G, et al. Predictors of health-related quality of life in patients with chronic liver disease. Aliment Pharmacol Ther. 2009;30:469-76.

14. Newton JL, Pairman J, Wilton K, Jones DE, Day C. Fatigue and autonomic dysfunction in non-alcoholic fatty liver disease. Clin Auton Res. 2009;19:319-26. 
15. Newton JL, Jones DE, Henderson E, Kane L, Wilton $\mathrm{K}$, Burt AD, et al. Fatigue in non-alcoholic fatty liver disease (NAFLD) is significant and associates with inactivity and excessive daytime sleepiness but not with liver disease severity or insulin resistance. Gut. 2008:57:807-13.

16. Gerber L, Otgonsuren M, Mishra A, Escheik C, Birerdinc A, Stepanova M, et al. Non-alcoholic fatty liver disease (NAFLD) is associated with low level of physical activity: a population-based study. Aliment Pharmacol Ther. 2012;36:772-81.

17. Kallman J, O'Neil MM, Larive B, Boparai N, Calabrese L, Younossi ZM. Fatigue and health-related quality of life (HRQL) in chronic hepatitis $C$ virus infection. Dig Dis Sci. 2007:52:2531-9.

18. Cinar S, Ozdogan OC, Alahdab Y. Impact of education provided by nurses on quality of life, anxiety, and depression in patients receiving hepatitis $C$ virus therapy. Gastroenterol Nurs. 2015;38(5):343-7.

19. Fabregas BC, de Avila RE, Faria MN, Moura AS, Carmo RA, Teixeira AL. Health related quality of life among patients with chronic hepatitis C: a crosssectional study of sociodemographic, psychopathological and psychiatric determinants. Braz J Infect Dis. 2013;17:633-9.

20. Teuber G, Schafer A, Rimpel J, Paul K, Keicher C, Scheurlen M, et al. Deterioration of health-related quality of life and fatigue in patients with chronic hepatitis C: Association with demographic factors, inflammatory activity, and degree of fibrosis. J Hepatol. 2008;49:923-9.

\section{Submit your next manuscript to BioMed Central and we will help you at every step:}

- We accept pre-submission inquiries

- Our selector tool helps you to find the most relevant journal

- We provide round the clock customer support

- Convenient online submission

- Thorough peer review

- Inclusion in PubMed and all major indexing services

- Maximum visibility for your research

Submit your manuscript at www.biomedcentral.com/submit 